Review began 11/11/2021 Review ended 11/14/2021 Published 11/15/2021

๑) Copyright 2021

Sarwar et al. This is an open access article distributed under the terms of the Creative Commons Attribution License CC-BY 4.0. which permits unrestricted use, distribution, and reproduction in any medium, provided the original author and source are credited.

\section{Treatment of Inferior Vena Cava Thrombosis by Endovascular Stenting: A Case Report}

\author{
Usman Sarwar $^{1}$, Nikky Bardia ${ }^{1}$, Maulikumar Patel ${ }^{1}$, Bassam Omar ${ }^{1}$, Christopher Malozzi ${ }^{1}$, Amod \\ Amritphale ${ }^{1}$, Ghulam Awan ${ }^{1}$ \\ 1. Division of Cardiology, University of South Alabama, Mobile, USA
}

Corresponding author: Usman Sarwar, usmanaimc@gmail.com

\begin{abstract}
Optimal treatment of inferior vena cava (IVC) thrombosis remains unclear, especially given the contraindications to anticoagulation use and because interventional options remain limited. We present a case of a 62-year-old man with advanced liver cirrhosis who developed IVC thrombosis with symptoms of severe abdominal pain and leg swelling. IVC flow was restored via successful recanalization with a transjugular and common femoral approach after deploying a $22 \times 70 \mathrm{~mm}$ Wallstent. On follow-up, the patient had a resolution of his symptoms.
\end{abstract}

Categories: Cardiology, Internal Medicine

Keywords: endovascular procedures, internal jugular vein, computed tomography, deep vein thrombosis, inferior vena cava

\section{Introduction}

Inferior vena cava (IVC) thrombosis can lead to considerable enfeebling. There are many causes for thrombosis forming in the venous system [1], some of the most common being inherited thrombophilia, malignancy, prolonged immobilization, and cirrhosis. Although the mainstay of acute thrombosis is anticoagulation, many patients are not candidates for anticoagulation, especially those with advanced liver cirrhosis or coexisting esophageal varices. Until recently, the treatment for acute thrombosis if anticoagulation failed was a surgical bypass of the obstructive vein, which carries an elevated risk of mortality and morbidity and a high failure rate. Now, however, with advancements in endovascular techniques, percutaneous angioplasty with stenting is the preferred treatment of choice $[2,3]$.

\section{Case Presentation}

The patient was a 62 -year-old male with a past medical history of liver cirrhosis secondary to hepatitis C, tobacco use, and post-stent coronary artery disease, who initially came to the hospital for elective left and right heart catheterization as a pre-transplant evaluation. Physical examination showed abdominal distension and diffuse tenderness with the presence of prominent superficial abdominal veins. A computed tomography (CT) scan of the abdomen with contrast was obtained immediately. The CT showed an occlusive thrombus of the IVC extending from the renal veins to the level of the cavoatrial junction. Thrombus was also observed in the portal vein, and multiple subcutaneous varicosities were found. Initially, a plan was made to start the patient on anticoagulation, but because of the patient's history of advanced cirrhosis, large esophageal varices on recent endoscopy, and thrombocytopenia, we concluded that the patient was not a candidate for anticoagulation. Given that the patient had significant abdominal distention with pain that did not improve even after therapeutic paracentesis; we inserted a stent in the IVC to relieve the patient's pain as a palliative procedure to improve his quality of life.

Right internal jugular (IJ) and right femoral vein accesses were obtained for the procedure. A $6 \mathrm{~F}$ pigtail diagnostic catheter was advanced from the right IJ to the right atrium, and contrast was injected into the right atrium that showed an occluded IVC at the junction of the right atrium. Another pigtail catheter was advanced through the right femoral vein and an inferior venogram was performed that showed the IVC was $100 \%$ occluded $2 \mathrm{~cm}$ above the renal veins (Figures $1 A, 1 B$ ). 


\section{Cureus}

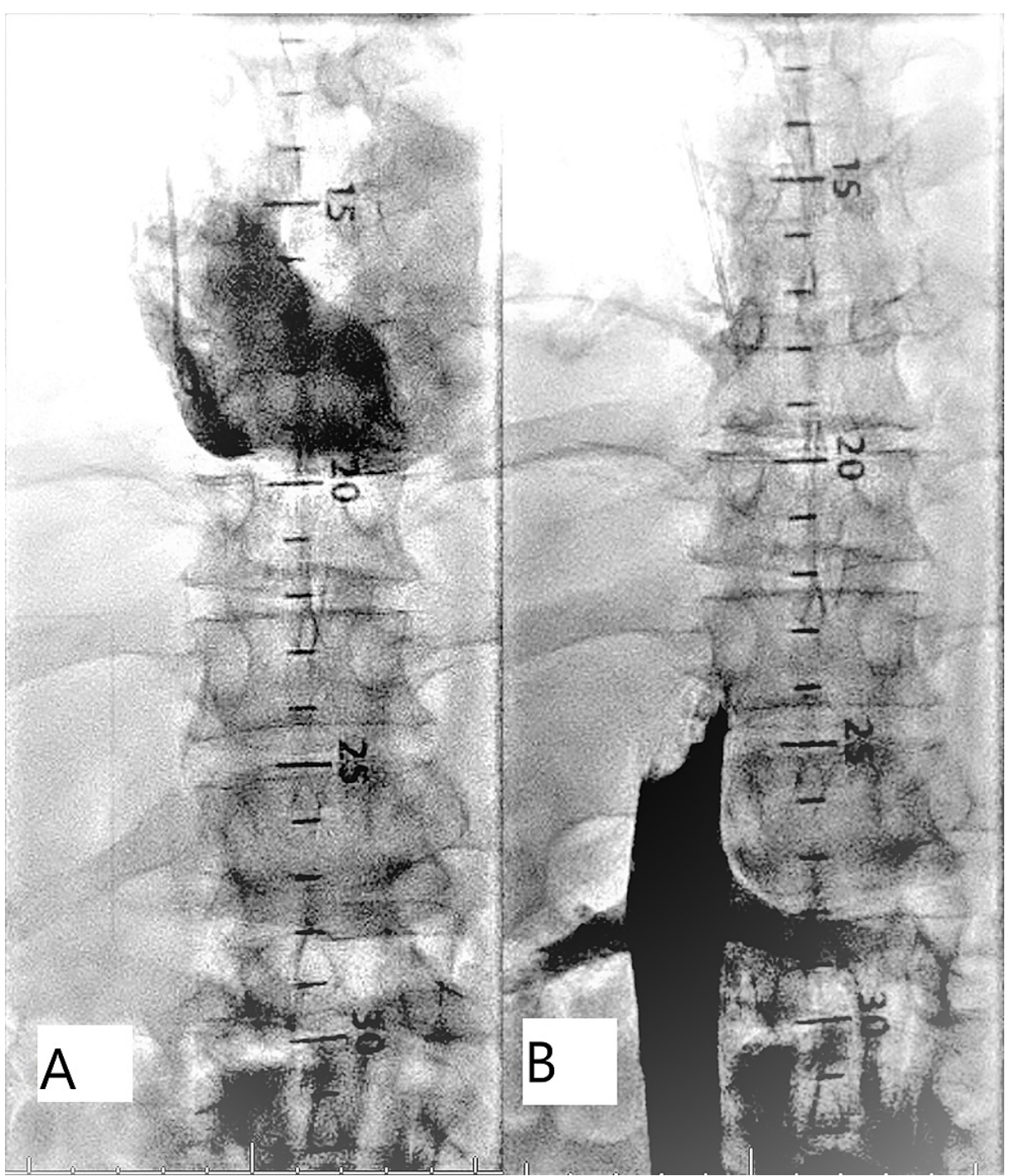

FIGURE 1: (A, B) Injection of iodine contrast showing an occluded IVC at the level of the right atrium and above the renal veins in various angiographic views

IVC - inferior vena cava

A Glidewire advantage was advanced through the right femoral vein but was unable to cross the $100 \%$ occluded IVC. Then, a 7-French Swan-Ganz catheter was tried and was successfully advanced through the IVC all the way to the right atrium. A Swan wire was inserted through the Swan-Ganz catheter. Then, a multipurpose catheter was advanced over the Swan wire into the right atrium, and the Swan-Ganz wire was successfully replaced with a Glidewire Advantage (Figure $2 A$ ). Initially, a $9 \times 80$ Mustang balloon was used to perform the IVC ballooning; after IVC ballooning; however, the inferior venogram showed no flow to the IVC, which was still $100 \%$ occluded. Then, a $22 \times 70 \mathrm{~mm}$ Wallstent was advanced via the right femoral vein to the right atrial side. The stent was deployed with a considerable waist in the mid area (Figure $2 B$ ). After stent placement, an $18 \times 60$ Boston Scientific esophageal balloon was successfully used to post-dilate the stent (Figure 2C). 


\section{Cureus}

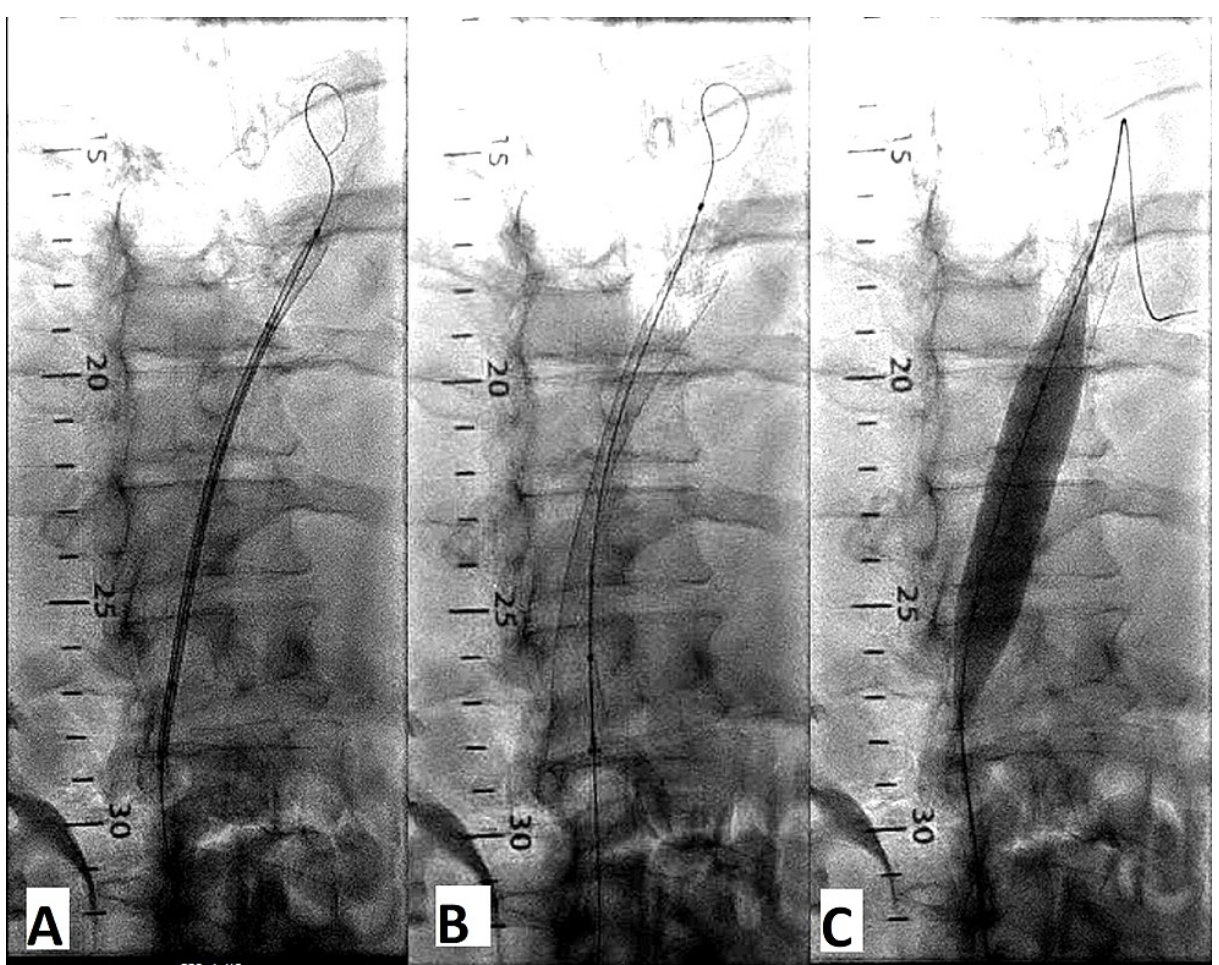

FIGURE 2: Successful wiring of IVC thrombus (A), Wallstent deployed (B), and post-dilation with Boston Scientific esophageal balloon (C)

The final venogram (Figures $3 A, 3 B$ ) and digital subtraction imaging mode showed excellent flow in the IVC to the right atrium. Small clots floating around at the lower edge of the stent above the renal artery were successfully removed with a 7-Fr snare. Usually, if IVC occlusion is of thrombosis in etiology anticoagulation is advised after venous stent placement, since our patient had an advanced liver failure with elevated INR, anticoagulation was not started [4]. 


\section{Cureus}

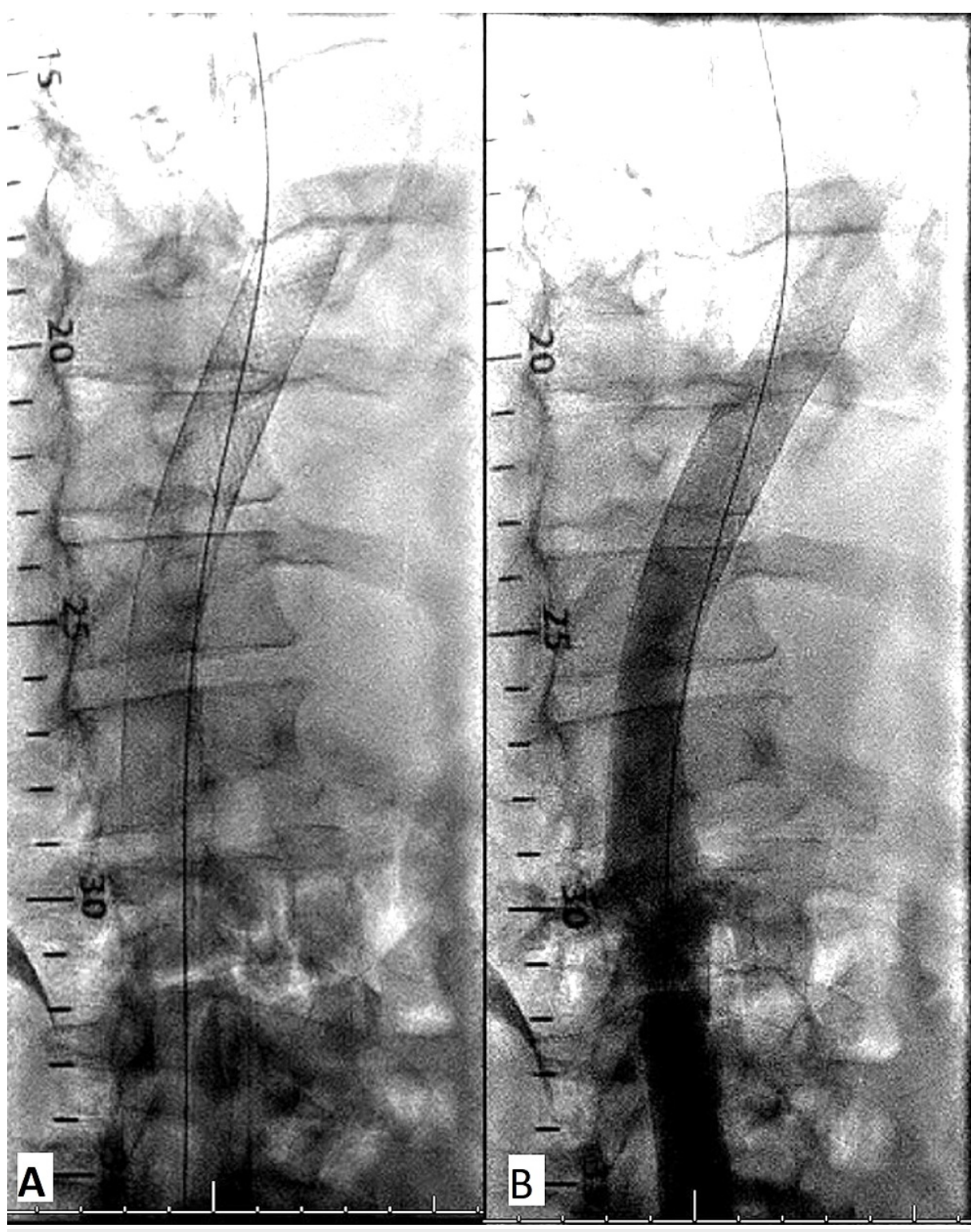

FIGURE 3: (A, B) Patent IVC after stent deployment on normal angiographic views

\section{Discussion}

We have described a patient with a past medical history of liver cirrhosis, now presenting with abdominal distension and significant pain due to IVC thrombus. The multistep intervention approach achieved patency of the IVC and symptomatic relief upon short-term follow-up. IVC thrombosis can cause severe complications if left untreated [5].

Initially, the mainstay of treatment had been conservative therapy with anticoagulation. If the treatment failed, however, a surgical approach with bypass was employed, which carries high morbidity and mortality. Now, due to recent advancements in percutaneous intervention techniques, venous stenting, especially in larger veins (IVC and iliac), has been proven to relieve outflow obstruction with an improvement of postthrombotic syndrome. Studies have shown that venous stenting has a high patency rate at 12 months, with a low complication rate and good procedural success $[6,7]$.

\section{Conclusions}

Acquired IVC thrombosis can result from deep vein thrombosis extension into the IVC, spontaneous thrombus formation, venous stasis due to external compression, or thrombosis related to a prior IVC filter when anticoagulation is contraindicated. Interventional techniques appear to be a feasible approach with acceptable risk and symptom relief. 


\section{Cureus}

\section{Additional Information \\ Disclosures}

Human subjects: Consent was obtained or waived by all participants in this study. Conflicts of interest: In compliance with the ICMJE uniform disclosure form, all authors declare the following: Payment/services info: All authors have declared that no financial support was received from any organization for the submitted work. Financial relationships: All authors have declared that they have no financial relationships at present or within the previous three years with any organizations that might have an interest in the submitted work. Other relationships: All authors have declared that there are no other relationships or activities that could appear to have influenced the submitted work.

\section{References}

1. Harris RD: The etiology of inferior vena caval obstruction and compression . CRC Crit Rev Clin Radiol Nucl Med. 1976, 1:57-86

2. Robbins MR, Assi Z, Comerota AJ: Endovascular stenting to treat chronic long-segment inferior vena cava occlusion. J Vasc Surg. 2005, 41:136-40. 10.1016/j.jvs.2004.10.024

3. Browse NL, Burnand KG, Irvine AT: Deep Vein Thrombosis: Pathology. Diseases of the Veins, 2nd edition . StatPearls Publishing, Treasure Island, FL; 1999. 10.1002/9781444317633.ch47

4. Xiao N, Kush RD: Antithrombotic therapy after venous stent placement. Vascul Endovascul Rev. 2020, 3:10. 10.15420/ver.2020.06

5. Grøtta O, Enden T, Sandbæk G, et al.: Patency and clinical outcome after stent placement for chronic obstruction of the inferior vena cava. Eur J Vasc Endovasc Surg. 2017, 54:620-8. 10.1016/j.ejvs.2017.07.003

6. Häusler M, Hübner D, Delhaas T, Mühler EG: Long term complications of inferior vena cava thrombosis . Arch Dis Child. 2001, 85:228-33. 10.1136/adc.85.3.228

7. van Vuuren TM, Doganci S, Wittens CH: Patency rates and clinical outcomes in a cohort of 200 patients treated with a dedicated venous stent. J Vasc Surg Venous Lymphat Disord. 2018, 6:321-9. 10.1016/j.jvsv.2017.09.013 